\title{
Rhizomes, Weak Links and Far Flung Networks: Empowering women's space in Tropical Asia
}

\author{
Anita Lundberg \\ Arts and Social Sciences, James Cook University, Singapore
}

\begin{abstract}
The United Nations declaration of the 'International Day of the Tropics' intends to raise awareness of the importance of the tropical regions of the world - from their ecological and cultural diversity, to their unequal share of the burden of poverty. The date of the international day of the tropics on the $29^{\text {th }}$ June each year, also celebrates the anniversary of the launch of the inaugural State of the Tropics 2014 report by Nobel Laureate Aung San Suu Kyi. This link to 'The Lady', as she is simply referred to by admirers, reminds me of an earlier time, twenty years previously, when Suu Kyi gave a recorded keynote address (she was still under house arrest) for the NGO Forum on Women which was also held in conjunction with the UN Fourth World Conference on Women, in China.

This connection between the tropics and women matters because many parts of the tropics continue to struggle against poverty and it is well documented that women and children bear the largest burden of poverty. The tropics are home to a reported $40 \%$ of the world's population, with that population undergoing immense growth. Estimates are that by 2050 more than two-thirds of the world's children under 15 years of age will be living in the tropics. This means the tropical zones of the world are also home to a vast number of women whose voices are striving to be heard.

This paper examines, in an exploratory voice, how women's networks contribute to their empowerment, especially in regions of tropical Asia. Influenced by interdisciplinary theories of network science and the philosophy of rhizomatics, the paper analyses the power of networks across multiple plateaux. Starting with the networks evoked in a feminine artwork, the analysis flings across to women's networks - those that are empowered and those that remained disempowered and finally emerges through education networks.
\end{abstract}

Keywords: women, empowerment, networks, rhizomatics, education, tropical Asia

\section{Opening - Women's Space}

'The education and empowerment of women throughout the world cannot fail to result in a more caring, tolerant, just and peaceful life for all.' 
I

' $m$ sitting in my university office in Singapore looking at the artwork that hangs above my desk. The piece is in the style of Asian pop art: bright photo-montages and graphics. In the left corner is the image of an elderly Malay woman wearing traditional tudung (headscarf), kebaya (blouse) and sarong, feet in plastic sandals, body hunched over her wooden stall selling kue (cakes). The old woman is positioned as if about to fall off the side of the artwork. Behind her, to the right, is a colour-saturated image of a street cart, ES CENDOL printed across its front in Bahasa Indonesia, jars and canisters arranged inside; the famous shavedice desert of South East Asia with its variations of pandan infused green worm-like rice jelly, coconut milk and gula malaka (palm sugar). Such carts are fading from the bustling streets of Asian cities. At the centre-right of the artwork is a portrait-style image of a young woman, sari draped across one shoulder in South Indian style. She faces forward looking obliquely past the viewer, her lips slightly parted - about to speak or perhaps to smile; a whole life ahead of her. Mandala circles appear around the young woman's head, a motif of the 1960s hippie movement that has recently recurred in Boho-Chic fashion; the West's appropriation of symbols from India. Dispersed throughout the artwork are prints of Peranakan tiles, the ones found on Straits Chinese heritage houses of Penang, Melaka and Singapore - the old Malay ports which drew colonial cross-cultural maritime networks of trade and labour. Stylised Chinese characters run down from the upper right corner of the artwork stating "Peking Opera". Interspersed throughout are images of flowers: lotus, hibiscus, peony. This is a feminine work of art - women's space.

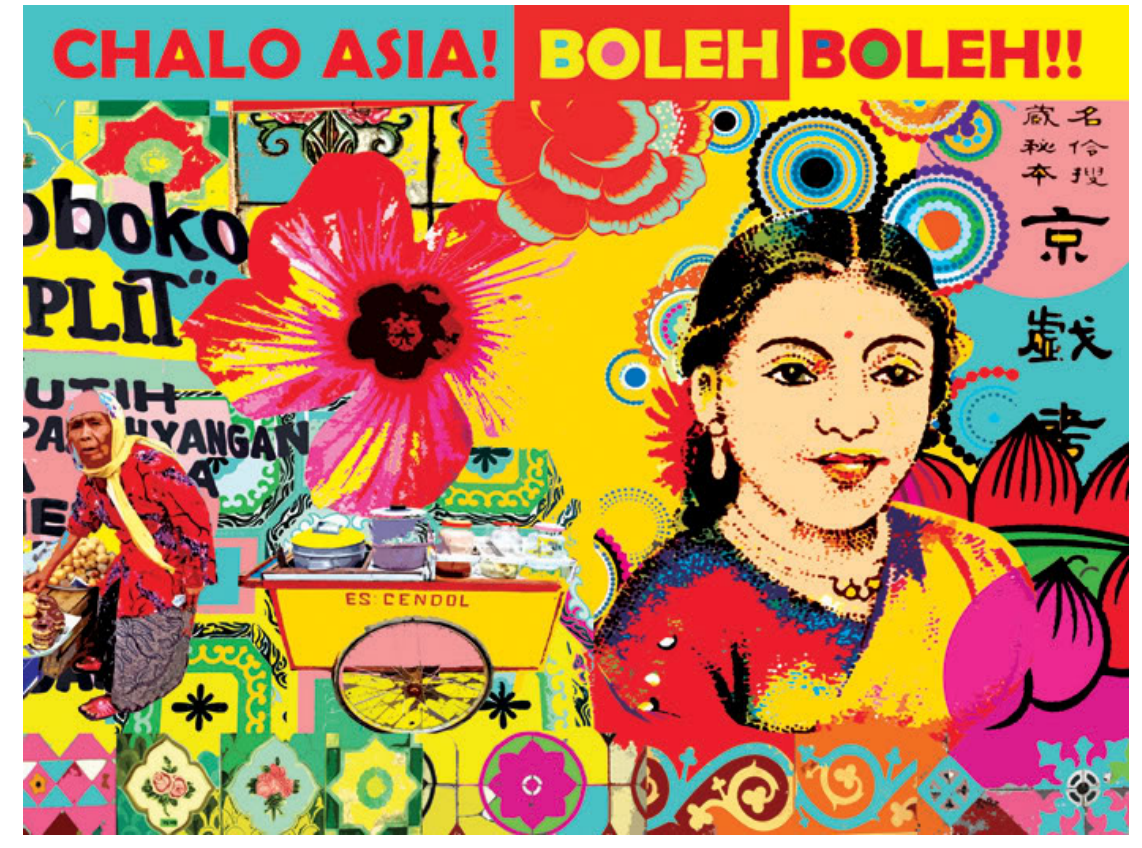

Figure 1. Ketna Patel, “Chalo Asia Boleh Boleh” Print 9/100, 2015

Across the top of the artwork are the printed words Chalo Asia! Boleh Boleh!! in a combination of Hindi and Malay. Given the long history of South Indian, Chinese and Indonesian migration and trade through Singapore, the words could have been in Tamil, various dialects of Chinese, or in Indonesian. In English the words shout out: Go Asia! Can Can!! 
The networks evoked through the images of this artwork: street food vendors, colonial trade and labour networks, the appropriation of images from the East into Western counter-culture and then contemporary fashion trends, multiculturalism symbolised in tiles, clothes, languages and flowers, demonstrate that networks are ancient as well as contemporary. They exist in the everyday workings of life and can be analysed across multiple plateaux. They are pervasive, subtle and powerful.

\section{A Network Narrative}

The story of how this artwork came to be on the wall of my university office requires a short narrative that rides the links of contemporary networks. The story begins as I was flying out of north Borneo having just climbed Mount Kinabalu and traversed the via ferrata - hanging by wires off the mountain precipice to overcome a fear of heights in a quest to empower myself. The Air Asia inflight magazine has an article about Women on a Mission, a philanthropic network of women located in Singapore who challenge themselves to extreme endurance treks in order to remember the fears and challenges that face all women, to increase awareness of issues of gender inequality and violence, and fund raise through innovative marketing campaigns and events. The money is donated to other international - locally led philanthropic networks that concentrate on women's causes. Recently a team from Women on a Mission had climbed the Himalayas (Santhinathan, 2015).

As the aeroplane taxis into Changi Airport, that Singapore hub for flights from around the globe, I walk through the vast connection of terminals with their networked travelators and escalators, my phone connected to WiFi. One hand is Google-searching the website of Women on a Mission. Emblazoned across the site's homepage are the words 'CHALLENGING OURSELVES TO EMPOWER WOMEN'. The philanthropy network includes Singaporean and overseas women, many of cross-cultural descent - French, Swiss, Filipina, British of Indian descent or of Dutch descent, Russian, South African and Chinese from Brunei. They have worked internationally in roles across marketing, banking, childhood education, luxury brands, social entrepreneurship, radio and news presenting, art, jewellery and fashion design, photography, writing, social activism, racehorse training, as well as corporate philanthropy. Professional titles include: Global Director, Executive Director, CEO and Founder. Their education spans many disciplines from arts to business. Awards are numerous (www.womenmission.com).

The webpage announces an upcoming art event. I RSVP online while seamlessly negotiation the airport surveillance and transport networks - swiping my passport through the scanner system and placing my thumb on the biometrics detector. Another escalator goes down to the underground rapid transit network. The driverless train approaches, doors slide open, the automated announcement tells me - in Tamil, Malay, Mandarin and English - to "mind the platform gap". I step inside simultaneously sending off an email to one of the organisers whose photograph appeared in the inflight magazine, requesting to know more about their philanthropic network. 
A couple of weeks later I'm standing in the lounge room of a large private 'black and white' colonial house that has been turned into an art gallery for the evening's charity event. In front of me, eyes staring obliquely from one of the artworks, is the pop art image of that young Indian woman. The artist is standing beside me. We are deep in discussion about the art piece; an international crowd is milling all around. I learn later that the British-Indian Ketna Patel grew up in Africa, lived in Singapore for many years where she met her English artist husband, and that they currently reside in Wales with frequent visits to India - both are back in Singapore for this charity event. Men are never far from this networked women's space. Later in the night there is the auction of a specially commissioned art piece that is conducted by one of the husbands of the Women of a Mission network. Women and men of various cultures and nationalities mingle, children run around playing in intercultural groups. During the main speech it is announced that a new organic perfume, in commemoration of the women's Himalaya trek, has been released, and that proceeds of the evening's event will go to AWARE (Association for Women for Action and Research), a Singapore gender equality advocacy and support network. After the speeches I speak to the Association's representative - networking to invite AWARE to the university as guests in my first year Anthropology subject which brings together young students from around Asia as well as from Europe, over half of whom are young women. As the evening begins to wind down I return to look at the artwork - already picturing it hanging in my office, a reminder of the importance of women's space and networks.

Although the women's space of the above narrative at first appears highly empowered and empowering, if we pause to pull at the threads of these networks, we find two striking points. Firstly, none of these women were born into the position of power they now appear to hold. Each has struggled to get to where they are, and have at times failed. Each of these women at some time has also had to face sexism, some have been physically abused or raped, many have also had to deal with racism, and some with homophobia. What they have in common is the ability to keep striving in the face of adversity, and all recognise the need to give back to women, to empower other women. Secondly, the women networked in this story are connected only through tenuous ties. These are not strong community networks, what makes this networked narrative interesting are the weak links - how different clusters of women's networks are brought into contact through lines that draw together through such abstract ideas as philanthropy, and art, and the efforts of a feminist advocacy. The network has a far reach precisely because of these weak ties.

\section{Networks \& Rhizomes}

As the world entered the new millennium we encountered not only 'the Asian Century' (Robertson \& Lundberg, 2013), but also the simultaneous full-blown age of networks and exponential ecological fragility. Contemporary theorists of network science don't just write about networks, they engage with digital technologies; thus, virtual spaces have influenced theoretical work in network science. Similarly, as we encounter an increased awareness of the intricate webs of ecological systems philosophers have been turning to images-of-thought inspired by nature. One such image is the rhizome (Lundberg, 2013a, 2013b). In turn, these theories affect the way we understand the dynamics of power. 


\section{Network science theory}

Emerging out the space of physics and mathematics, new network science demonstrates the properties and processes of networks on and across multiple plateaux (Barabási, 2003; Buchanan, 2002; Watts, 2003; Lundberg, 2013a, 2013b). These include: brain functions, diasporas of people, food networks, neoliberal globalised manufacture, transport networks, telecommunications, trade, social networks (physical and online), viral networks (virtual and medical), financial networks, ecological networks, as well as the networks of cities - street lighting, sewerage, water distribution networks. Importantly, network science can also shed light on women's networks.

Recently, network science has been taken up in the humanities and social sciences. At James Cook University, a university with two campuses in the tropical north of Australia and one campus in Singapore, network theories form the basis of the cross-disciplinary first year Bachelor of Arts subject Our Space: Networks, Narratives and the Making of Place (Kuttainen \& Lundberg, 2011-2015) which, appropriately, at the university's offshore campus in Singapore, is tutored in new 'networked' classrooms (Lundberg, 2013b). ${ }^{1}$

Crossing between disciplines is not unusual in new network analysis. Indeed, the scientists Barabási and Watt's inspiration for their theory came from two strangely linked phenomena: a social psychology experiment devised back in the counter-cultural days of the 1960s, and a more recent trivia game developed by bored university students. To understand how people are linked in webs of connections, the psychologist Stanley Milgram used the snail mail postal network to demonstrate that people could get a letter from one place and person to an unknown recipient in another location in approximately six relay postings. This became known as six degrees of separation. This same notion of six degrees also appeared as the basis to a trivia game that entailed finding the links (six or less) between the Hollywood actor Kevin Bacon (a prolific actor but not at that time a star) and any other actor. At the turn of this century the network science theorists were profoundly shocked by the idea that over six billion people could be linked through just six connections. The scientists' aim was to model this phenomenon through a mathematical graph (Buchanan, 2002, pp. 14-15; Hilton \& Talas, 2009). The graph shows that the notion of six degrees of separation is real and demonstrates specific characteristics - it is a 'small-world' network.

\footnotetext{
${ }^{1}$ The network theories taught in this subject have, in turn, lead to cross disciplinary research projects and diverse case studies. For instance: mapping the international flow of magazines across the Pacific during the 1920-1930s golden age of passenger liners (Kuttainen, 2014); interpreting experiences of students on exchange through a discourse analysis of their blog posts (Lundberg, Stasiewicz-Bieńkowska, \& Enhörning Singhateh, 2012); demonstrating the research links of the TransOceanik network of the CNRS (Lundberg, 2013a); and analysing the connected learning space of a digitally networked classroom (Lundberg, 2013b).
} 
What this reveals is that links between people are not spread out evenly; social life clusters. The networks of transportation, the internet, economics, biology and ecology likewise present small-world phenomena. In each network, most nodes are linked to only a few other nodes. But some nodes have lots of links - most of which are weak connections. These are hubs that shorten the paths between all the nodes in the entire network. The key principle of six degrees is that it is not about strong connections; it is the weak ties have the power to expand links and networks.

An important principle of network science theory is the ability to connect between network clusters. In other words, is it not about who you know in your local community which forms your strong connections (virtual or real); what becomes significant - and demonstrated through graph mathematics - are the weak connections. The weak ties, like a vector, create a line of flight that jumps from your cluster over to another cluster thereby connecting you with a whole new group of people. Furthermore, this pattern is evident across multiple plateaux: the technology of postal networks, which rely on transport networks; the actor/movie networks of Hollywood, which could equally apply to Bollywood or the Chennai Tamil movie industry. And the same pattern applies to ecological networks.

\section{Rhizomatic Theory}

Network science resonates with the ecophilosophy of rhizomatics. Developed by the philosopher Gilles Deleuze and psychoanalyst Félix Guattari (1987/1980) this thought experiment can be imagined through the botanical rhizome. The theory evokes images of the tropical rhizomatic roots of turmeric, ginger or galangal - which, in turn, reminds us of the networked spice trade routes which involved movements of people, the crossing of cultures, and is invoked through the materiality of Peranakan buildings in Singapore and Malaysia, or Chettia heritage buildings in South India.

The underground rhizome of the turmeric, ginger or galangal, is transversal with nodes connecting lines in all directions. And like this root, rhizomatic theory and research allows for multiple, non-hierarchical entry and exit points in the analysis and presentation of research. Rhizomatic analysis necessitates connection and diversity of content, where any node of the rhizome can connect to any other (Deleuze and Guattari, 1987/1980, p. 8). It also suggests that anything can come under analysis, including women's spaces of all textures: a feminine pop art work, philanthropic networks, interdisciplinary research networks, conference networks, social media networks, local women's action networks, literacy networks, networks of micro-financing, water collection networks in slums.

A defining feature of rhizomes is their ability to rupture. If we break off a node of turmeric and replant it elsewhere, it will grow into a new network. Significantly there is no origin or hierarchy to the rhizome: every node holds the potential to expand the network, or start a new network. The horizontally networked image of rhizomes can be juxtaposed to the hierarchical image of the tree with its deep penetrating tap root, upright linear trunk, and bifurcating branches. It is this tree image on which traditional western philosophy hangs its notions of evolution, racism, 
development, progress, patriarchy and the elitism of education as the 'tree of knowledge'. While a tree model works according to notions of linear hierarchical development, rhizomes indicate spatial horizons of ruptures and connections and vectors. Knowledge in a rhizome scenario is like the network image of the world wide web where links cluster, break, and fling across to a new cluster.

However, the philosophy of rhizomatics is never simply anti-tree; in fact, the banyan tree of tropical Asia is a spectacular example of rhizomatic imagery. Sprouting as an epiphyte via bird faeces in a host tree, it sends out adventitious aerial roots that grow downwards to the earth to take root, then form new branches, that become trunks. The original tree dies, but the banyan continues to spread (Geerlings \& Lundberg, 2016; Lundberg, 2008, 2013b). The banyan tree, as the national tree of India, with one of the largest and most ancient specimens in the world located in Tamil Nadu, may be an exemplar image of the concept of rhizomatics - an organic imaginary of networks.

All network spaces have the potential to be rhizomatic and empowering. Yet, these spaces also hold hierarchical aspects, including acting as vehicles of surveillance and disempowerment. There is no general theory that can provide one solution to the problem of women's space and gender equality. The importance of rich and varied local case studies can not be overlooked - the importance of women's stories arising from the details of everyday life are of growing importance in this new century dominated by big data. Women's spaces need women's voices, in all their differences.

\section{Go Asia! Can Can!!}

The 'Asia Century' is often portrayed in financial terms as rising incomes, rising consumerism and rising cities. In this economic imaginary, the problem of inequality is narrowed to monetary terms. However, the concept of women's space, as the potential for gender equality, necessitates the improvement of wellbeing across society to offer greater opportunities in broader indicators of wellbeing: education, income, health, choice of employment and involvement in decision-making (State of the Tropics, 2014, pp.171-172).

These indicators form an ecology; nodes in an interconnected matrix, like a rhizome or a banyan tree. Each indicator as a node of investigation can also be studied as a cluster in a larger network - and networks involve inherent relations of power.

\section{Education and gender empowerment}

Education is a key node in human development and in creating spaces of gender equality. 'Education represents opportunity. At all ages, it empowers people with the knowledge, skills and confidence they need to shape the future' (UNESCO, 2011).

Female empowerment is an important factor influencing gender equality in a society. Girls' and women's access to education is a necessary aspect of empowerment to all females. 
Empowerment leads to increased economic opportunities for women, as well as access to transformative and decision making roles. The measurement of progress includes higher ratios of women in all levels of education, increasing businesses opportunities for women, creating greater freedom and mobility, and encouraging and enabling women in decisionmaking and political roles. Gender equality requires further initiatives in female empowerment to increase the number of women in secondary and tertiary education and in formal employment, including at senior levels. (State of the Tropics, 2014, pp. 378-381; UN Women, n.d.)

Large scale studies report that improved access and engagement with education at all levels has assisted more women to enter the formal labour market and business ownership. Business ownership for women in developing nations has also been established through microfinance or microentrepreneur funding, providing women with opportunities to apply practical skills, earn an income and develop management skills. These businesses can generate income for their female owners and possible employment opportunities for other members of the community. Women are considered more likely than men to reinvest money earned from microentrepreneur initiatives and employment back into their children's wellbeing, including in education and health (State of the Tropics, 2014, pp. 380-381).

However, women are also caught up in the traditions and power biases of cultures. Women may struggle to gain independence in the domestic sphere, their influence or power may be reduced to the local community, and those women who do gain wealth may still feel compelled to privilege male children with food, education, and health care, while simultaneously burdening female children with the allocation of domestic duties. Again, education of women - at all levels and all ages - becomes a key in creating social awareness towards a culture of equality.

A study by Tata and Prasad (2008), which used network science theory to analyse the relation between microfinance and women's networks notes women's strong ties to the close-knit networks of local community. While these strong ties are useful in the start up phase of microfinance initiatives, Tata and Prasad (2008) argue that sustained growth of business requires weak ties - those links that can fling from one cluster across to other clusters in order to create larger networks for entrepreneurial engagement. Women often lack these larger networks and do not feel they have the right, the skills, or the means to link to these larger regional, national or global networks. More research needs to be done in this area through grounded, local case studies.

Despite worldwide attention and increased funding for female education, barriers still exist that prevent girls from starting and completing secondary school; while university, for most women, is not even a dream. The main barriers to girls attending secondary school are poverty, followed, in many cultures, by the undervaluing of girls (Fancy, Unterhalter, Vaughan, \& Nussey, 2012). Interlaced with these barriers is the burden of chores carried by girls. Children from poorer households are less likely to attend school, added to this, girls are more likely than boys not to be educated due to poverty. Poverty, in turn, is related to access to drinking water - which also has a gender dimension. In homes without household access to drinking 
water, it is women and girls who have the primary responsibility of collecting water. The long term consequences of this burden of girls' chores is significant: inhibiting involvement in education, affecting opportunities to engage in productive work and income generation, and impacting on women's involvement in broader social and political activities. (State of the Tropics, 2014, p.404)

Opportunities provided by higher levels of education can support women and girls to engage equally with men in society. However, in order to achieve women's space, women need to engage with men and men with women. Men are encouraged to use their influence at all levels of society to help deconstruct gender stereotypes and gender-related discriminatory practices. There still remains a much higher ratio of men in decision-making occupations, and men have an important role in participating in processes towards balancing gender equality. This balancing is required at all levels of society and across all domains. It requires working collaboratively to challenge cultural traditions and perceptions, as well as legislation and social policy that influence the discrimination of women in education and decision-making practices (Malhotra, Pande, \& Grown, 2003; State of the Tropics, 2014, pp. 382-383).

\section{Alumni networks}

Education entails literacy, the acquisition of skills, the analysis of information, and a widening ability to think through diverse problems and communicate ideas. As students progress through assignments they are not just proving that they have gained knowledge; importantly, they also gain of sense of empowerment - for each assignment entails facing fears and challenges, and demonstrating endurance. However, there is something more. Access to increasingly higher levels of education also offers openings to more far flung networks. Primary schools provide access to a cluster of other students located in a local community, secondary education draws together students from greater distances, and university education may entail moving away from home and engagement in state, national or international networks. Each level of education enables students to connect to wider networks.

With this in mind, the expressions 'school tie networks' and 'old boy networks' suddenly take on a greater meaning. These phrases once referred to male only members of elite British schools and universities and their networks of social and business connections. The terms literally and figuratively invoked the tie of the school's uniform and the branding of school. Today this elitism is less evident, and we use the term alumni (the singular alumnus refers to men; alumna is the feminine term that is rarely seen or heard). Increasingly high schools and universities promote online networks with their alumni, while cross-alumni organisations offer networking opportunities for clusters of university graduates who studied in a particular country or internationally. From the old nineteenth and twentieth century strong tie elite networks associated with hierarchies, the new twenty-first century alumni networks can create weak ties that span across institutions and borders offering far flung international networks. These alumni networks of young, educated, global citizens are also spaces of empowerment; and they are potential nodes for gender equality. As academics and recipients of the advantages of education and of alumni networks we have an obligation to include gender awareness in 
universities, across all departments, so that our alumni graduate with an understanding and appreciation of gender equality.

\section{Closing - Women's Space}

Because there is no one way of empowering women, because case studies of woman's struggles for empowerment in order to bring about equality are going to vary according to the specifics of place - those local nodes in international history, culture, society, politics and economy - we need a way of imagining women's spaces as clusters, arising from women's networked narratives, in all their multitudes of verbal, visual or written texts - whether these be stories, images, textiles or articles.

The prefatory quote at the beginning of this paper is from Aung San Suu Kyi's video recorded keynote address for the 1995 NGO Forum on Women held in conjunction with the UN Fourth World Conference on Women in Beijing, China, 1995. Over 31,000 women from 200 countries attended the events which signalled a worldwide network of women working towards gender equality, development and peace. The recipient of many humanitarian awards, including the Nobel Peace Prize in 1991 and the Jawaharlal Nehru Award for International Understanding in 1993, Aung San Suu Kyi, wearing signature flowers in her hair, remains an international role model of women's empowerment.

I would like to close this paper with another quote, this time from the $25^{\text {th }}$ African Union Summit, July 2015. The theme of that year's summit was the 'Year of Women's Empowerment and Development'. The quote is from a panel speech by the Special Envoy of the UN High Commissioner for Refugees:

'We need policies for long-term security that are designed by women, focused on women, executed by women - not at the expense of men, or instead of men, but alongside and with men.'

'There is no greater pillar of stability than a strong, free and educated woman, and there is no more inspiring role model than a man who respects and cherishes women and champions their leadership.' (Angelina Jolie, 11 June via Facebook 14 July, 2015).

The Special Envoy of the UN High Commissioner for Refugees and award winning actress and filmmaker with the charismatic smile is also the recipient of a Freedom Award 2007, and a Jean Hersholt Humanitarian Award 2013. Angelina Jolie uses her Hollywood power to draw attention to, and speak out on women's rights as they intertwine with development and refugee issues across the globe.

Twenty years have passed between the opening quote to this paper by Aung San Suu Kyi, audio recorded in 1995, and the closing quote by Angelina Jolie, blasted across social media, in 2015. During this time the world has witnessed a whole generation grow into young adults. As I write this last sentence, I look up from my computer screen to the art hanging on the wall 
in my university office. The image of that young woman continues to stare obliquely out of the artwork. Flowers are scattered here and there, her lips slightly parted perhaps in the glimmer of a smile, or maybe about to speak out. She could be twenty years old, about the age of my students. In the span of her twenty years we are yet to create a women's space, and to empower networks for all genders. Her eyes gaze out towards the future.

\section{Acknowledgements}

A version of this paper was first presented as the Keynote address for the International Conference on Women and Social Transformation hosted by the Centre for Women's Studies, Department of Women's Studies at Alaggapa University, Tamil Nadu, India, 21-22 August 2015. I would like to acknowledge the important work of the Centre for Women's Studies and the warm welcome of their management, academics and students. The subject 'Our Space: Networks, Narratives and the Making of Place' was first designed with Dr Victoria Kuttainen in 2010. I still remain inspired by the networks opened up through that collaborative effort with Dr Kuttainen.

\section{References}

Barabási, A. (2003). Linked: how everything is connected to everything else and what it means for business, science, and everyday life. New York, NY: Plume.

Buchanan, M. (2002). Nexus: Small worlds and the groundbreaking science of networks. New York, NY: W.W. Norton \& Company.

Deleuze, G., \& Guattari, F. (1987/1980). Introduction: Rhizome (B. Massumi, Trans.). In A Thousand Plateaus (pp. 3-28). Minneapolis, MN: University of Minnesota Press (Original work published in 1980).

Fancy, K., Unterhalter, E., Vaughan, R.P. \& Nussey, C. (2012). The State of the World's Girls, 2012. Retrieved from Plan International website: https://plan-international.org/publications/state-worldsgirls-2012-learning-life.

Geerlings, L.R.C., \& Lundberg, A. (2016). Global discourses and power/knowledge: Theoretical perspectives on futures of higher education in the Asian Century. Manuscript submitted for publication.

Hilton, C. (Producer) \& Talas, M. (Director). (2009). Six degrees of separation [Documentary]. Essential Media and Entertainment in association with Real Pictures: BBC Broadcasting.

Jolie, A. (2015, July 14). Angelina Jolie's powerful speech about ending sexual violence against women [Facebook post].

Kuttainen, V. (2014). Trafficking literature: travel, modernity, and the middle ground of Canadian and Australian middlebrow print cultures. International Journal of Canadian Studies, 48, 85-103.

Kuttainen, V \& Lundberg, A. (2011-2015). BA1002 Our Space: Networks, Narratives and the Making of Place. Subject Outline, James Cook University.

Lundberg, A. (2013a). TransOceanik links: research networks and the space-place of colloquiua. In A. Lundberg (Guest Ed.) TransOceanik Special Issue Etopic, 12(1), 1-21.

Lundberg, A. (2013b). Get connected! Collaborative adventures in networked spaces of learning.' Proceedings of the International Conference on Emerging Research Paradigms in Business and Social Sciences. Dubai, United Arab Emirates: Middlesex University.

Lundberg, A. (2008). Material poetics of a Malay house, The Australian Journal of Anthropology, 19(1), 1-16.

Lundberg, A., Stasiewicz-Bieńkowska, A., \& Enhörning Singhateh, A. (2012). Border crossing networks: Virtual reality. In S. Fan, T. Le, Q. Le, \& Y. Yue (Eds.), Innovative research in a 
changing and challenging world (pp. 81-94). Launceston, Australia: Australian Multicultural Interaction Institute.

Malhotra, A., Pande, R., \& Grown, C. (2003). Impact of investments in female education on gender equality. Washington DC: International Center for Research on Women.

Patel, K. (2015). Chalo Asia Boleh Boleh [Artwork]. Retrieved from: http://www.ketnapatel.com/site/paintings/

Robertson, R., \& Lundberg, A. (2013). Asia-Australia nexus: An educational challenge. In P. Mandal (Ed.), Proceedings of the International Conference on Managing the Asian Century (pp. 13-21). Singapore: Springer.

Santhinathan, C. (Ed.) (2015, March). Women on a Mission. Travel 3Sixty, 136-137.

State of the Tropics (2014). State of the tropics report. Australia: James Cook University. Retrieved from: http://stateofthetropics.org/

Suu Kyi. A.S. (1995, August 31). Gifts of Speech [Video recording]. Keynote address delivered at the NGO Forum on Women, Beijing, China. Retrieved from: https://www.youtube.com/watch?v=9leLB-VRUo8

Tata, J., \& Prasad, S. (2008). Social capital, collaborative exchange and microenterprise performance: the role of gender. International Journal of Entrepreneurship and Small Business, 5(3/4), 373388.

UNESCO (2011). Education counts: Towards the Millennium Development Goals. Retrieved from: http://unesdoc.unesco.org/images/0019/001902/190214e.pdf.

UN Women (n.d.). About UN Women. Retrieved from: http://www.un.org/womenwatch/daw/daw/index.html

Watts, D.J. (2003). Six degrees: the science of a connected age. New York, NY: W. W. Norton \& Company.

Women on a Mission (n.d.). Challenging ourselves to empower women. Retrieved from: www.womenmission.com 